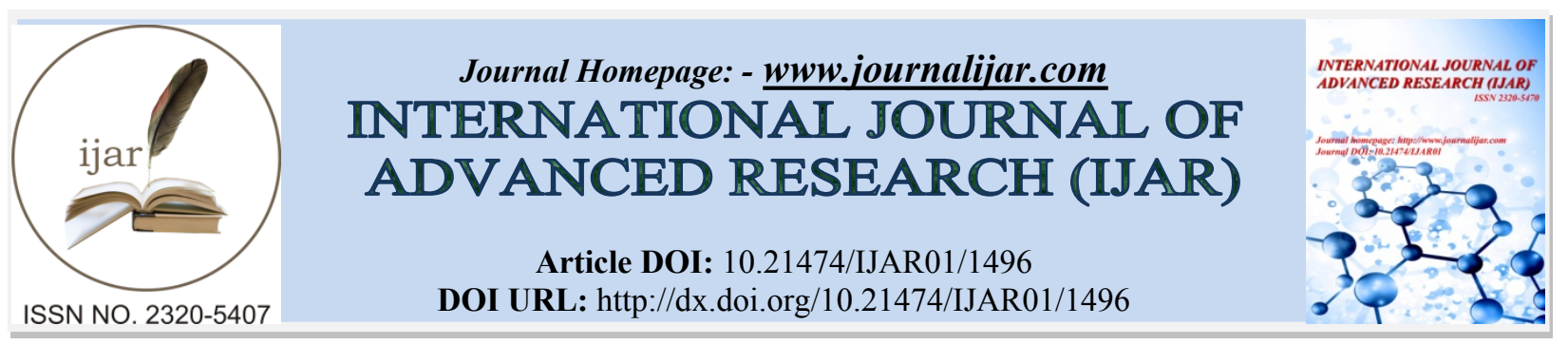

RESEARCH ARTICLE

\title{
GREEN APPROACH TOWARDS SYNTHESIS OF 3-SUBSTITUTED-5-CARBONYLMETYL-1,2,4- OXADIAZOLES WITHOUT ANY SOLVENT AND CATALYST VIA TRANSAMIDOXIMATION.
}

\section{G. B. Dharma Rao ${ }^{*, 1,2}$ and Ravi Gujjula ${ }^{2}$.}

1. Discovery Centre, Process Technology Development Division, Defence R. \& D. Establishment, Jhansi Road, Gwalior - 474002 (M.P), India.

2. Department of Chemistry, Kommuri Pratap Reddy Institute of Technology, Hyderabad - 501301 (TS), India.

\section{Manuscript Info}

Manuscript History

Received: 12 July 2016

Final Accepted: 19 August 2016

Published: September 2016

\section{Key words:-}

1,2,4-Oxadiazoles, Methyl $\beta$-Ketoester,

Amidoxime, trans-Amidoximation,

Green Chemistry.

\section{Abstract}

An efficient, simple, environmentally benign, cost-effective and expeditious etiquette for the construction of biologically momentous 3 -substituted-5-carbonylmetyl-1,2,4-oxadiazole derivatives in one-pot has been developed by the reaction of methyl $\beta$-ketoesters with an assortment of amidoximes via transamidoximation transformation, which further experience intramolecular cyclization followed by dehydration at $110^{\circ} \mathrm{C}$. The current environmentally benign protocol offers the advantages of simple methodology, cost-efficiency, short reaction times, neat reaction profiles without solvent and catalyst shows a novel direction in green synthesis along with great yield.

Copy Right, IJAR, 2016,. All rights reserved.

\section{Introduction:-}

The green chemistry revolution is providing an enormous number of challenges for chemists including innovation and spreading out of non-hazardous and straightforward environmental friendly chemical procedures for selective synthesis by identifying different reaction conditions and solvents for much enhanced selectivity, energy preservation and even less perilous waste generation are not attractive and inherently safer chemical products. With these tasks however, there are an equal number of opportunities to discover and apply new chemistry, to improve the economics of chemical manufacturing and to boost up the much-tarnished image of chemistry. In recent years, the synthesis of organic scaffolds under greener circumstances have acknowledged substantial attention and emerged as a leading mission in organic synthesis. A green protocol incorporates a new approach to the synthesis, processing and application of chemical substances in such a manner as to diminish the use and/or generation of harmful substances, threats to health and the environment. The main intention of green chemistry is to perform reactions under solvent-free, ${ }^{1}$ catalyst-free, ${ }^{2}$ and environmentally benign catalyst ${ }^{3}$ conditions.

The construction of new heterocyclic scaffold derivatives which illustrate pharmacological and biological significance stands for a most important assignment in synthetic and medicinal chemistry. 1,2,4-Oxadiazoles are amazing classes of $\mathrm{N}$-heterocyclic compounds showing their broad spectrum of valuable promising biological activities, such as muscarinic agonists, ${ }^{4}$ serotoninergic (5-HT3) antagonists, ${ }^{5}$ benzodiazepine receptor agonists, ${ }^{6}$ dopamine ligands, ${ }^{7}$ inhibitors of monoamine oxidase, ${ }^{8}$ sphingosine-1-phosphate-1 $\left(\mathrm{S}_{1} \mathrm{P}_{1}\right)$ receptor agonist ${ }^{9}$ can say that 1,2,4-oxaziazole core unit have been explored in past years. 1,2,4-Oxadiazoles have often been used as hydrolysis-resisting bioisosteric replacements for esters and amides ${ }^{10}$ and as dipeptide mimetics ${ }^{11}$ in a number of

Corresponding Author:- G. B. Dharma Rao.

Address:- Department of Chemistry, Kommuri Pratap Reddy Institute of Technology (KPRIT), Hyderabad 416

- 501301 (TS), India. 
pharmacologically imperative molecules. The biological and synthetic values place this moiety at prestigious paramount position in medicinal chemistry research.

Bearing in mind the noteworthy relevancies in the fields of medicinal, biological and synthetic organic chemistry, there has been marvelous curiosity in developing efficient procedures for the synthesis of 1,2,4-oxadiazoles and quite number of synthetic procedures have been accounted in the literature for the synthesis of 1,2,4-oxadiazoles derivatives, which include the reaction of amidoxime with activated carboxylic acid derivatives such as acid chlorides, ${ }^{12}$ fluorides, ${ }^{13}$ anhydrides (BOP-Cl),${ }^{14}$ or active esters ${ }^{15}$ using coupling reagents like, DCC, ${ }^{16}$ DIC/HOBt,${ }^{17}$ TBTU, ${ }^{18} \mathrm{CDI} .{ }^{19}$ Besides this, metal catalysts, ${ }^{20} \mathrm{TBAF},{ }^{21}$ microwave technique, ${ }^{22} \mathrm{NaH},{ }^{23} \mathrm{NaOMe},{ }^{24} \mathrm{~K}_{2} \mathrm{CO}_{3}{ }^{25}$ and condensation of malonic diesters with amidoximes under neutral and solvent-free conditions ${ }^{26}$ were also reported. However, most of the synthetic protocols reported so far experienced from several difficulties, such as the obligation of drastic reaction conditions (strong acids, high temperatures), prolonged reaction time, use of toxic and expensive reagents, use of hazardous solvents and catalysts, formation of by-products which resulted in poor yields of the desired target product. Obviously, many of these catalysts, coupling reagents and solvents are not at all satisfactory in the environment of green synthesis. As a consequence, look for new methods/ reagents/ catalysts to overcome these limitations are still an important experimental challenge to synthetic medicinal chemists. In the light of these shortcomings and as a part of our program towards the green synthesis, ${ }^{27}$ in this paper we wish to address a simple transamidoximation transformation proceeds very efficiently, which further undergo intramolecular cyclization followed by dehydration in the course of stirring a mixture of neat precursors such as amidoxime (1) and methyl $\beta$ ketoester (2) at $110^{\circ} \mathrm{C}$ requiring no solvent and catalyst, and producing 3-aryl substituted-5-carbonylmetyl-1,2,4oxadiazole derivatives (3) in high yields (Scheme 1) with broader scope of application.

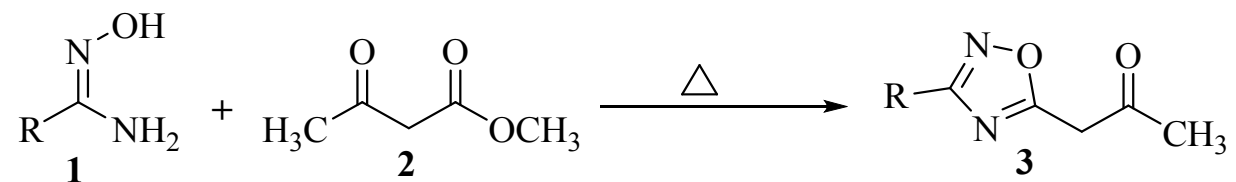

Scheme 1:- Synthesis of 3,5-subsituted-1,2,4-oxadiazoles via transamidoximation reaction under greener conditions.

\section{Experimental:-}

Materials:-

Arylnitriles, hydroxylamine and methyl $\beta$-ketoester were purchased from Sigma-Aldrich, India.

\section{Synthesis of 1,2,4-oxadiazoles:-}

A mixture of methyl $\beta$-ketoester $(1.5 \mathrm{mmol})$ and an amidoxime $(1.0 \mathrm{mmol})$ was charged in a $25 \mathrm{ml}$ round bottomed flask and gently heated at $110^{\circ} \mathrm{C}$ (oil-bath) with constant mechanical stirring under solvent and catalyst free conditions. The reaction was proceeds under nitrogen atmosphere to remove the relatively volatile methyl alcohol through distillation condenser for a certain period of time as required for a complete reaction. The extent of the reaction was monitored by TLC, and after completion, the contents were cooled to room temperature give the crude product which is reasonably pure. However, recrystallization from hot ethanol provides the analytically pure 1,2,4oxadiazole desired product in $80-98 \%$ yield. This procedure is followed for the synthesis of all the 1,2,4-oxadiazole derivatives listed in Table 1. All the products are reported earlier and are identified by comparison of their IR, ${ }^{1} \mathrm{H}$, ${ }^{13} \mathrm{C}$ NMR and spectral data with those reported.

All the products are known compounds and were confirmed by IR, ESI-MS and NMR spectroscopic techniques. Spectroscopic data for some compounds are given below.

1-(3-benzhydryl-1,2,4-oxadiazol-5-yl)propan-2-one (Table 1, entry 4):- IR ( $\left.v_{\operatorname{Max}}\right)$ : 698, 847, 922, 1031, 1161, 1640, 1736, 2926, 3029, 3438. ${ }^{1} \mathrm{H}-\mathrm{NMR}\left(400 \mathrm{MHz}, \mathrm{CDCl}_{3}\right) \delta=2.218(\mathrm{~s}, 3 \mathrm{H}), 3.968(\mathrm{~s}, 2 \mathrm{H}), 5.616(\mathrm{~s}, 1 \mathrm{H}), 7.293-$ $7.310(\mathrm{~m}, 10 \mathrm{H}) .{ }^{13} \mathrm{C} \mathrm{NMR}\left(\mathrm{CDCl}_{3}\right) \delta=20.868,29.241,40.954,48.074,48.291,83.416,126.955,127.159,128.224$, $128.316,128.448,128.823,139.247,171.499,173.079,198.729$. ESI-MS: $m / z=293.62[\mathrm{M}+1]$.

1-(3-cyclohexyl-1,2,4-oxadiazol-5-yl)propan-2-one (Table 2, entry 5):- IR ( $\left.v_{\operatorname{Max}}\right)$ : 789, 824, 1162, 1361, 1586, $1641,1732,2857,2933 .{ }^{1} \mathrm{H}-\mathrm{NMR}\left(400 \mathrm{MHz}, \mathrm{CDCl}_{3}\right) \delta=1.260-1.460(\mathrm{~m}, 4 \mathrm{H}), 1.521-1.588(\mathrm{~m}, 2 \mathrm{H}), 1.809-1.841$ $(\mathrm{m}, 2 \mathrm{H}), 2.003-2.094(\mathrm{~m}, 2 \mathrm{H}), 2.301(\mathrm{~s}, 3 \mathrm{H}), 2.771-2.845(\mathrm{~m}, 1 \mathrm{H}), 4.014(\mathrm{~s}, 2 \mathrm{H}) \cdot{ }^{13} \mathrm{C} \mathrm{NMR}\left(\mathrm{CDCl}_{3}\right) \delta=20.744$, 
$25.345,29.245,30.134,35.312,41.005,83.255,169.756,172.170,173.815,198.732$. ESI-MS: $\mathrm{m} / \mathrm{z}=231.61$ $[\mathrm{M}+23]$.

1-(3-(4-methoxybenzyl)-1,2,4-0xadiazol-5-yl)propan-2-one (Table 1, entry 6):- IR ( $\left.v_{\operatorname{Max}}\right): 695,800,918,1178$, 1513, 1731, 2838, 2927, 3440, $3625 .{ }^{1} \mathrm{H}-\mathrm{NMR}\left(400 \mathrm{MHz}, \mathrm{CDCl}_{3}\right) \delta=2.265$ (s, 3H), $3.775(\mathrm{~s}, 3 \mathrm{H}), 3.982(\mathrm{~s}, 2 \mathrm{H})$, $4.016(\mathrm{~s}, 2 \mathrm{H}), 6.842-6.863$ (d, $J=8.4,2 \mathrm{H}), 7.217-7.239$ (d, $J=8.4,2 \mathrm{H}) .{ }^{13} \mathrm{C}$ NMR $\left(\mathrm{CDCl}_{3}\right) \delta=20.744,25.345$, $29.245,30.134,35.312,41.005,83.255,169.756,172.170,173.815,198.732$. ESI-MS: $m / z=269.59$ [M+23].

1-(3-(2,5-dichlorophenyl)-1,2,4-oxadiazol-5-yl)propan-2-one (Table 1, entry 9):- IR ( $\left.v_{\operatorname{Max}}\right): 806,821,899,803$, 1347, 1569, 1722, 2933, 2974. ${ }^{1} \mathrm{H}-\mathrm{NMR}\left(400 \mathrm{MHz}, \mathrm{CDCl}_{3}\right) \delta=2.368$ (s, 3H), 4.148 (s, 2H), 7.415-7.421 (d, $J=2.4$, $1 \mathrm{H}), 7.960-7.966(\mathrm{~d}, J=2.4,1 \mathrm{H}) .{ }^{13} \mathrm{C}$ NMR $\left(\mathrm{CDCl}_{3}\right) \delta=29.908,41.478,83.633,127.159,131.161,131.720$, 132.222, 133.017, 166.602, 172.906, 198.393. ESI-MS: $m / z=271.39[\mathrm{M}+1]$.

1-(3-(pyridin-2-yl)-1,2,4-oxadiazol-5-yl)propan-2-one (Table 1, entry 10):- IR ( $\left.v_{\text {Max }}\right)$ : 747, 803, 996, 1159, $1366,1640,1722,2924,3453 .{ }^{1} \mathrm{H}-\mathrm{NMR}\left(400 \mathrm{MHz}, \mathrm{CDCl}_{3}\right) \delta=2.354(\mathrm{~s}, 3 \mathrm{H}), 4.175(\mathrm{~s}, 2 \mathrm{H}), 7.440-7.455(\mathrm{~m}, 1 \mathrm{H})$, 7.853-7.877 (m, 1H), 8.113-8.133 (d, 1H), 8.788-8.800 (d, 1H). ${ }^{13} \mathrm{C} \mathrm{NMR}\left(\mathrm{CDCl}_{3}\right) \delta=29.780,41.384,123.138$, 125.557, 137.017, 145.827, 150.177, 168.221, 173.924, 198.965. ESI-MS: $m / z=204.57[\mathrm{M}+1]$.

1-(3-(4-bromophenyl)-1,2,4-oxadiazol-5-yl)propan-2-one (Table 1, entry 11):- IR ( $\left.v_{\text {Max }}\right)$ : 741, 839, 915, 1362, $1401,1563,1719 .{ }^{1} \mathrm{H}-\mathrm{NMR}\left(400 \mathrm{MHz}, \mathrm{CDCl}_{3}\right) \delta=2.357$ (s, 3H), $4.109(\mathrm{~s}, 2 \mathrm{H}), 7.616-7.638(\mathrm{~d}, J=5.2,2 \mathrm{H}), 7.934-$ $7.951(\mathrm{~d}, J=5.2,2 \mathrm{H}) .{ }^{13} \mathrm{C}$ NMR $\left(\mathrm{CDCl}_{3}\right) \delta=21.348,29.820,41.472,83.700,125.405,125.836,128.884,132.114$, 167.902, 173.218, 198.592. ESI-MS: $m / z=303.38[\mathrm{M}+23]$.

\section{Results and Discussion:-}

$\beta$-Ketoesters serves as an reliable synthon which were employed in synthesis of polymers, drugs, biologically dynamic compounds and also utilized as building blocks in the construction of complex natural products. ${ }^{28} \beta$ Ketoesters have also demonstrated to be a advanced synthon essentially for the reason that the occurrence of both electrophilic in addition to nucleophilic centers. $\beta$-Ketoesters easily underwent to acetylketene intermediate formed by the abolition of alcohol i.e removal of alkoxy moiety of $\beta$-ketoester and hydrogen adjacent to it under thermal conditions. Moreover, great deal of attention has been spent towards transamidoximation with lower homologue (methyl $\beta$-ketoester) than higher homologue (tert-butyl $\beta$-ketoester) with amidoxime under solvent and catalyst free conditions for the synthesis of corresponding 1,2,4-oxadiazole derivative.

As per our systematic studies ${ }^{29}$ intended towards the development of novel synthetic methodologies for widely used heterocyclic compounds inspired us to synthesize 1,2,4-oxadiazoles. Recently, we have reported the synthesis of $\beta$ ketoesters via transesterification ${ }^{27}$ transformation using methyl $\beta$-ketoester under solvent and catalyst free conditions at $110^{\circ} \mathrm{C}$ through acetylketene intermediate. To reveal the reactivity of acetylketene intermediate and applicability of above stated reaction conditions, herein we desire to report a simplistic synthesis of 1,2,4-oxadiazoles derivatives in one-pot condensation using methyl $\beta$-ketoester with a range of amidoximes via transamidoximation transformation, which further experience intramolecular cyclization followed by dehydration under solvent and catalyst free conditions at $110^{\circ} \mathrm{C}$. Transamidoximation is the exchange of alkoxy moiety of $\beta$-ketoester with amidoxime to form $O$-acyl amidoxime similar to trasesterification transformation.

In order to optimize the reaction conditions, the initial studies were conceded out on synthesis of 1,2,4-oxadiazole by making use of methyl $\beta$-ketoester and cyclohexyl amidoxime as model substrates (Table 1, Entry 5). The 1,2,4oxadiazole of cyclohexyl amidoxime was obtained in moderate yield (32\%), when methyl $\beta$-ketoester was refluxed for $3 \mathrm{~h}$ with equimolar amount of cyclohexyl amidoxime (1:1) in the absence of solvent and catalyst at $110^{\circ} \mathrm{C}$. The modest yield of 1,2,4-oxadiazole of cyclohexyl amidoxime is for the reason that the low formation of $O$-acyl cyclohexyl amidoxime through acetylketene intermediate i.e methyl alcohol and cyclohexyl amidoxime are in computation to react with reactive acetylketene intermediate. The acetylketene intermediate is reversible and it is highly reactive key intermediate in synthesis of 1,2,4-oxadiazole, $\beta$-ketoester and uracile. ${ }^{30}$ The cyclohexyl amidoxime was completely converted into 1,2,4-oxadiazole, which was obtained in $92 \%$ yield (Table 1, entry 5) via transamidoximation for the formation of $O$-acyl cyclohexyl amidoxime, which further undergo intramolecular cyclization followed by the dehydration with methyl $\beta$-ketoester through the parallel amputation of relatively volatile methyl alcohol by distillation from the reaction mixture. In this reaction, we surprisingly found the drastic change in reaction time form $3 \mathrm{~h}$ to $80 \mathrm{~min}$. This might be due to exhibiting the more increasing electron density on 
oxygen atom owing to the occurrence of conjugate moiety $\left(\mathrm{OH}-\mathrm{N}=\mathrm{C}-\mathrm{NH}_{2}\right)$ and parallel removal of methyl alcohol. 1,2,4-Oxadiazole product was achieved, when the amidoxime and methyl $\beta$-ketoester were used in a mole ratio of $1: 1.5$, which was identified by applying of GC-MS technique. The use of increased quantity of methyl $\beta$-ketoester did not enhance the desired product yield, whereas lower amount of methyl $\beta$-ketoester gave the modest yield due to the existence of equilibrium in transamidoximation transformation. It has also been observed that the same reaction conditions were carried out in refluxed solvents such as acetonitrile, dichloromethane, toluene, chloroform and THF to decrease the reaction time and increase the desired product yield. But we observed the lengthy reaction time and poor yields to furnished the 1,2,4-oxadiazole derivative (Figure 1). It seems the extraordinary advantages of the solvent-free reaction and negative role of solvent at least in this case.

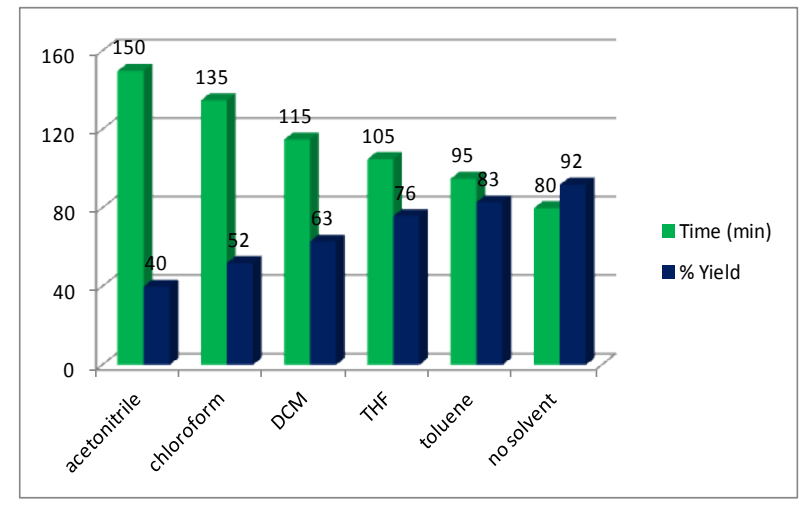

Figure 1:- Solvent effect on synthesis of desired product (Table 1, entry 5) detected by GC-MS technique.

With the inquisitiveness in dropping the reaction temperature, we executed the identical reaction of representative reactants at diverse temperatures of $90^{\circ} \mathrm{C}, 100^{\circ} \mathrm{C}$ and $110^{\circ} \mathrm{C}$ with constant reaction time $(80 \mathrm{~min})$. We analyzed the reaction mixture using ESI-MS technique and identified, $O$-acyl cyclohexyl amidoxime [ESI-MS $=143(\mathrm{M}+1)]$ at $90^{\circ} \mathrm{C}$, hydrated 1,2,4-oxadiazole derivative of cyclohexyl amidoxime [ESI-MS $=249(\mathrm{M}+23)$ ] at $100^{\circ} \mathrm{C}$ and dehydrated 1,2,4-oxadiazole derivative of cyclohexyl amidoxime [Table 1, entry 5, ESI-MS = $209(\mathrm{M}+1)$ ] respectively. On the source of above interpretation, it can be concluded that the reaction proceeds smoothly when amidoxime (1) and methyl $\beta$-ketoester (2) were used in mole ratio of 1: 1.5 under solvent and catalyst free circumstances at $110^{\circ} \mathrm{C}$ to affords the target 3,5-sbstituted 1,2,4-oxaziazole derivative in terms of reaction time and $\%$ yields.

The feasibility of optimized reaction conditions was further extended to the synthesis of more functionalized 3substituted-5-carbonylmetyl-1,2,4-oxadiazole derivatives via transamidoximation for the formation of $O$-acyl amidoxime, which further undergo intramolecular cyclization followed by dehydration and experiments were performed by making use of wide range of aryl amidoximes bearing electron-releasing and electron withdrawingsubstituent. It was found that in all the cases the reaction occurred smoothly and all the results are tabulated in Table 1. The Salient features of this methodology are as follows, (i) methyl $\beta$-ketoester is successfully transformed into 1,2,4-oxadiazole derivatives (ii) even bulkier amidoxime (Table 1, entries 4,9).

Table-1: Synthesis of 1,2,4-oxadiazoles using methyl $\beta$-ketoester and amidoxime under solvent and catalyst free conditions ${ }^{\mathrm{a}, \mathrm{b}}$<smiles>[R]C(N)=NO</smiles> 


\begin{tabular}{|c|c|c|c|c|}
\hline Entry & Amidoxime (1) & Time (min) & Product (3) & Yield (\%) \\
\hline 1 & & 60 & & 98 \\
\hline 2 & & 90 & & 87 \\
\hline 3 & & 75 & & 90 \\
\hline 4 & & 105 & & 88 \\
\hline 5 & & 80 & & 92 \\
\hline 6 & & 70 & & 94 \\
\hline 7 & & 100 & $\mathrm{O}_{2} \mathrm{~N}$ & 82 \\
\hline 8 & $\mathrm{NH}_{2}$ & 90 & & 92 \\
\hline 9 & $\mathrm{NH}_{2}$ & 120 & & 80 \\
\hline 10 & & 100 & & 86 \\
\hline 11 & & 120 & & 82 \\
\hline
\end{tabular}

aReaction conditions: amidoxime $(1.0 \mathrm{mmol})$, methyl $\beta$-ketoester $(1.5 \mathrm{mmol})$ refluxed at $110^{\circ} \mathrm{C}$ under solvent and catalyst free conditions.

${ }^{\mathrm{b}}$ All the reactions monitored by TLC and GC-MS. cIsolated yield.

On the basis of the above observations and the literature reports, a plausible reaction pathway for the formation of the 3-substituted-5-carbonylmetyl-1,2,4-oxadiazole derivatives via transamidoximation transformation is depicted in Scheme 2. Methyl $\beta$-ketoester (2) is easily rehabilitated into reactive acetylketene intermediate by the loss of relatively volatile methyl alcohol at $110^{\circ} \mathrm{C}$ temperature. The resulting acetylketene intermediate undergo transamidoximation transformation with amidoxime (1) to obtain the $O$-acyl amidoxime, which further experience a 
cyclization to afford the corresponding 3,5-substituted-1,2,4-oxadiazole derivative followed by the elimination of water molecule.

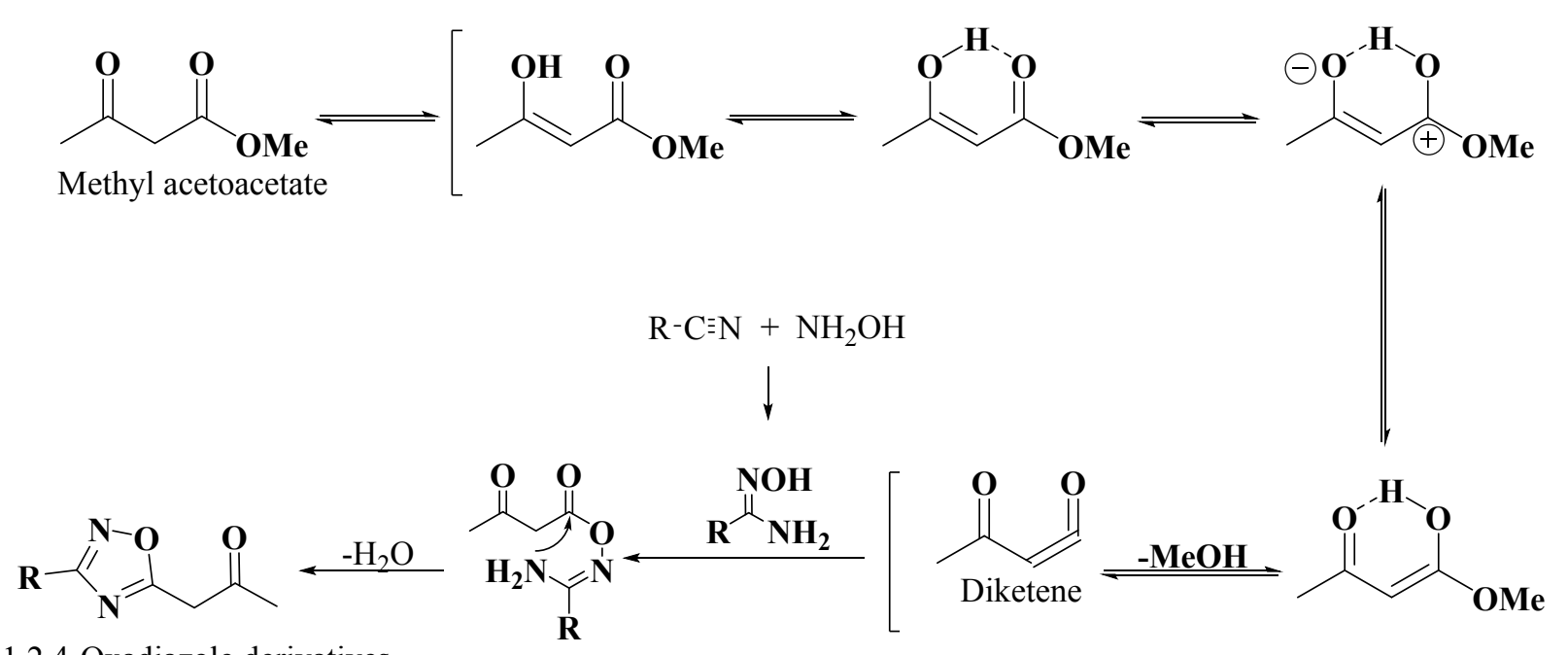

1,2,4-Oxadiazole derivatives

Scheme 2:- Proposed mechanism for the synthesis of 3,5-substituted-1,2,4-oxadiazole derivatives via transamidoximation.

\section{Conclusion:-}

In conclusion, we have demonstrated a efficient, expeditious and green protocol in terms of reducing the reaction times and increasing yields for the synthesis of 3-substituted-5-carbonylmetyl-1,2,4-oxadiazole derivatives of potential synthetic and pharmacological interest under solvent and catalyst free conditions via well recognized transamidoximation transformation (like transesterification). The most obvious merits of this enhanced protocol is the simple operation, easy work-up procedure, short reaction time, no hazardous catalysts, no corrosive, toxic solvents, inexpensive for the generation of structurally diversified 1,2,4-oxadiazole derivatives. We believed that, the advantages make this approach an attractive alternative for the synthesis of target heterocyclic scaffold and this is economical as well as environmentally benign procedure.

\section{Acknowledgements:-}

The authors express special gratitude to Dr. Ravi K Gujjula, Principal, KPRIT, Hyderabad for his keen interest and encouragement and also be grateful to DRDE, Gwalior.

\section{References:-}

1. G. Nagendrappa, Resonance, 7, 59 (2002), b) G. B. Dharma Rao, M. P. Kaushik, A. K. Halve, Tetrahedron Lett., 53, 2741 (2012), c) G. B. Dharma Rao, M. P. Kaushik, A. K. Halve, Heterocyclic Lett., 2, 411 (2012), d) G. B. Dharma Rao, M. P. Kaushik, Tetrahedron Lett., 52, 5104 (2011).

2. L. I. Koval, V. I. Dzyuba, O. L. Ilnitska, V. I. Pekhnyo, Tetrahedron Lett., 49, 1645 (2008).

3. T. Jin, S. Zhang, T. Li, Green chem., 4, 32 (2002).

4. B. S. Orlek, F. E. Blaney, F. Brown, M. S. G. Clark, M. S. Hadley, J. Hatcher, G. J. Riley, H. E. Rosenberg, H. J. Wadsorth, P. Wyman, J. Med. Chem., 34, 2726 (1991), b) T. Suzuki, H. Uesaka, H. Hamajima, T. Ikami, Chem. Pharm. Bull., 47, 876 (1999).

5. C. J. Swain, R. Baker, C. Kneen, J. Moseley, J. Saunders, E. M. Seward, G. Stevenson, M. Beer, J. Stanton, K. Watling, J. Med. Chem., 34, 140 (1991).

6. F. Watjen, R. Baker, M. Engelstoff, R. Herbert, A. Macleod, A. Knight, K. Merchant, J. Moseley, J. Saunders, C. J. Swain, E. Wong, J. P. Springer, J. Med. Chem., 32, 2282 (1989), b) J. P. Williams, K. Lavrador, Comb. Chem. HighThroughput Screen., 3, 43 (2000).

7. F. I. Carroll, J. L. Gray, P. Abraham, M. A. Kuzemko, A. H. Lewin, J. W. Boja, M. J. Kuhar, J. Med. Chem., 36, 2886 (1993).

8. M. Harfenist, D. J. Heuser, C. T. Joyner, J. F. Batchelor, H. L. White, J. Med. Chem., 39, 1857 (1996). 
9. Z. Li, W. Chen, J. J. Hale, C. L. Lynch, S. G. Mills, R. Hajdu, C. A. Keohane, M. J. Rosenbach, J. A. Milligan, G.-J. Shei, G. Chrebet, S. A. Parent, J. Bergstrom, D. Card, M. Forrest, E. J. Quackenbush, L. A. Wickham, H. Vargas, R. M. Evans, H. Rosen, S. Mandala, J. Med. Chem., 48, 6169 (2005).

10. G. D. Diana, D. L. Volkots, T. J. Hitz, T. R. Bailey, M. A. Long, N. Vescio, S. Aldous, D. C. Pevear, F. J. Dutko, J. Med. Chem., 37, 2421 (1994).

11. S. Borg, R. C. Vollinga, M. Labarre, K. Payza, L. Terenius, K. Luthman, J. Med. Chem., 42, 4331 (1999).

12. K. D. Rice, J. M. Nuss, Bioorg. Med. Chem. Lett., 11, 753 (2001).

13. C. K. Sams, J. Lau, Tetrahedron Lett., 40, 9359 (1999).

14. S. Borg, G. Estenne-Bouhtou, K. Luthman, I. Csöregh, W. Hesselink, U. Hacksell, J. Org. Chem., 60, 3112 (1995).

15. J. L. Buchanan, C. B. Vu, T. J. Merry, E. G. Corpuz, S. G. Pradeepan, U. N. Mani, M. Yang, H. R. Plake, V. M. Varkhedkar, B. A. Lynch, I. A. MacNeil, K. A. Loiacono, C. L. Tiong, D. A. Holt, Bioorg. Med. Chem. Lett., 9, 2359 (1999).

16. A. L. Braga, D. S. Lüdtke, E. E. Alberto, L. Dornelles, W. A. S. Filho, V. A. Corbellini, D. M. Rosa, R. S. Schwab, Synthesis, 10, 1589 (2004).

17. A. Hamzé, J.-F. Hernandez, P. Fulcrand, J. Martinez, J. Org. Chem., 68, 7316 (2003).

18. M. D. Evans, J. Ring, A. Schoen, A. Bell, P. Edwards, D. Berthelot, R. Nicewonger, C. M. Baldino, Tetrahedron Lett., 44, 9337 (2003).

19. T. L. Deegan, T. J. Nitz, D. Cebzanov, D. E. Pufko, J. A. Jr. Porco, Bioorg. Med. Chem. Lett., 9, 209 (1999).

20. J. R. Young, R. J. DeVita, Tetrahedron Lett. 39, 3931 (1998), b) R. M. Srivastava, A. de Almeida Lima, O. S. Viana, M. J. da Costa Silva, M. T. J. A. Catanho, J. O. F. de Morais, Bioorg. Med. Chem. 11, 1821 (2003).

21. A. R. Gangloff, J. Litvak, E. J. Shelton, D. Sperandio, V. R. Wang, K. D. Rice, Tetrahedron Lett., 42, 1441 (2001).

22. M. Adib, A. H. Jahromi, N. Tavoosi, M. Mahdavi, H. R. Bijanzadeh, Tetrahedron Lett. 47, 2965 (2006).

23. L. J. Street, R. Baker, T. Book, C. O. Kneen, A. M. Macleod, K. J. Merchant, G. A. Showell, J. Saunders, R. H. Herbert, S. B. Freedman, E. A. Harley, J. Med. Chem. 33, 2690 (1990).

24. P. Sauerberg, J. W. Kindtler, L. Nielsen, M. J. Sheardown, T. Honore, J. Med. Chem., 34, 687 (1991).

25. K. K. D. Amarasinghe, M. B. Maier, A. Srivastava, J. L. Gray, Tetrahedron Lett. 47, 3629 (2006).

26. W. Du, W. K. Hagmann, J. J. Hale, Tetrahedron Lett., 47, 4271 (2006).

27. G. B. Dharma Rao, B. N. Acharya, M. P. Kaushik, Tetrahedron Lett., 54, 6644 (2013).

28. R. J. Clemens, Chem. Rev., 1986, 86, 241. b) J. Otera, Chem. Rev., 93, 1449 (1993).

29. G. B. Dharma Rao, B. N. Acharya, S. K. Verma, M. P. Kaushik, Tetrahedron Lett. 52, 809 (2011), b) G. B. Dharma Rao, B. Anjaneyulu, M. P. Kaushik, Tetrahedron Lett. 55, 19 (2014),c) G. B. Dharma Rao, M. P. Kaushik, Int. Arch. Sci. Technol. 13, 25 (2013).

30. T. Sasaki, T. Yoshioka, Bull. Chem. Soc. Japan, 42, 3008 (1969).( References there in) 